\title{
Analysis of Space Charge Formation in LDPE in the Presence of Crosslinking Byproducts
}

\author{
Nuriziani Hussin ${ }^{1,2}$ and George Chen ${ }^{2}$ \\ ${ }^{1}$ School of Electrical System Engineering, University Malaysia Perlis, 02600 Arau Perlis, Malaysia \\ ${ }^{2}$ School of Electronics and Computer Science, University of Southampton, SO17 1BJ, UK
}

\begin{abstract}
Cross-linking byproducts are suspected to be the main contributing factor in space charge formation observed in XLPE. To investigate the mechanism behind this phenomenon, low density polyethylene was soaked into three main crosslinking byproducts, acetophenone, $\alpha$ methylstyrene and cumyl alcohol, and space charge measurements were performed using the Pulse Electroacoustic technique (PEA). It has been found that soaking LDPE in cumyl alcohol introduces more charges into the system, with homocharges and heterocharges accumulating within the sample compared to the additive free sample. In contrast, $\alpha$ methylstyrene and acetophenone reduce the amount of accumulated charges. In terms of charge decay, all three byproducts enhance the decay process in the insulator. Further investigations were conducted in conditions where two byproducts are present in a sample. The results shows that acetophenone is a dominant byproduct in determining the charge density patter built up during the charging process, whilst the rate of charge decay is observed to be high in the presence of $\alpha$-methylstyrene in the sample.
\end{abstract}

Index Terms - Space charge, LDPE, XLPE, crosslinking byproducts, acetophenone, cumyl alcohol, alpha methylstyrene.

\section{INTRODUCTION}

CROSSLINKED polyethylene, commercially known as XLPE is widely used as an insulating material in high voltage cable insulation. Crosslinking is a process that joins different polymer chains together by a chemical reaction. Polyethylene can undergo the process of crosslinking to form XLPE by connecting the end branches to different PE chains. The crosslinking process retains the electrical properties of LDPE and improves certain properties of PE such as the mechanical properties at elevated temperatures, resistance to deformation and stress-cracking as well as improving tensile strength and modulus.

It has been found that, after crosslinking with Dicumyl Peroxide (DCP), the crosslinking byproducts such as acetophenone, $\alpha$-methylstyrene and cumyl alcohol have a significant influence on electrical properties of XLPE power cables [1]. Polymer is extruded such that the PE surrounds the conductor and cured at a high temperature and high pressure. The PE is then melted and the peroxide decomposes to induce the crosslinking process. The chemical structure and their melting point of the byproducts are presented in Table I.

Despite of its ability to withstand high temperatures, the ease in which space charge accumulates in a XLPE system

Manuscript received on 23 March 2011, in final form 20 September 2011.
Table 1. Properties of The Crosslinking Byproducts.

\begin{tabular}{c|ccc}
\hline \multirow{2}{*}{$\begin{array}{c}\text { Byproducts } \\
\text { Acetophenone }\end{array}$} & $\begin{array}{c}\text { Melting } \\
\text { Chemical } \\
\text { Structure } \\
\left({ }^{\circ} \mathrm{C}\right)\end{array}$ & $\begin{array}{c}\text { Proportion of } \\
\text { total } \\
\text { byproducts in } \\
\text { XLPE }(\mathrm{Wt} \%)\end{array}$ \\
\hline Cumyl alcohol & & -24 & 0.455 \\
\hline
\end{tabular}

becomes the main concern when employing this material in insulation systems [2]. With the existence of space charge in the insulator, the breakdown process might occur at much lower voltage due to local field enhancement, ionization and electromechanical energy storage [3]. Much research has shown that a few factors 
can be associated with the formation of space charge in XLPE, such as the crosslinking structure, anti-oxidants and moisture [4]. However, it is believed that crosslinking byproducts are one of the major contributors in space charge accumulation [5] which is why a degassing process is applied to remove byproducts from the crosslinked structure after the crosslinking process. This paper intends to gain a deeper understanding of space charge accumulation mechanisms in XLPE and address how individual byproducts can affect space charge formation within the polymer. This research is vital and serves as an alternative to finding replacement material in typical insulation systems.

\section{EXPERIMENT PROCEDURES}

\subsection{SAMPLE PREPARATION}

Four samples were prepared for this investigation, additive free LDPE circular films with diameter $36 \mathrm{~mm}$ and $180 \mu \mathrm{m}$ thickness were soaked for $2 \mathrm{~h}$ in $\alpha$ methylstyrene, acetophenone and cumyl alcohol. All samples were prepared at room temperature, except for those soaked in cumyl alcohol which were treated at 80 ${ }^{\circ} \mathrm{C}$. The reason for using LDPE over XLPE is to eliminate any possibility of having more than one byproduct in the system. Even though previous studies by N. Hirai [6] show that space charge characteristics in LDPE and degassed XLPE are similar, it has been proven that under stress, the amount of space charge accumulation differs [7]. In addition, the possibility of having byproduct-free XLPE via degassing cannot be guaranteed [8], thus, LDPE is chosen over XLPE.

The absorption rates of the byproducts into the LDPE film can be observed by percentage weight increase and the rates are plotted in Figure 1. These values are similar to the values that are reported in [9]. It is worth addressing here that this percentage weight of byproducts per sample film is not relative to the actual percentage of the byproducts in commercial XLPE, as emphasised before the focus of this research is to compare the effect of the three byproducts in space charge accumulation.

The rate of decay of these byproducts in the soaked samples can be observed in Figure 2. When the soaked samples are left in an open environment (OS), the byproduct decay rapidly $(1-4 \% \mathrm{wt})$. $\alpha$-methylstyrene decays fastest and acetophenone decays slowest. However when using the PEA method, the sample is placed in between two electrodes in a closed environment, this causes the byproducts to be retained for a longer period within the sample. This result is also shown in Figure 2 marked as (CS). Space charge measurements are conducted within $2 \mathrm{~h}$, and are considered that any loss in byproduct is negligible, i.e. the amount of byproducts is almost constant throughout the experiment. This consideration is based on the rate of decay of these byproducts in the soaked samples.

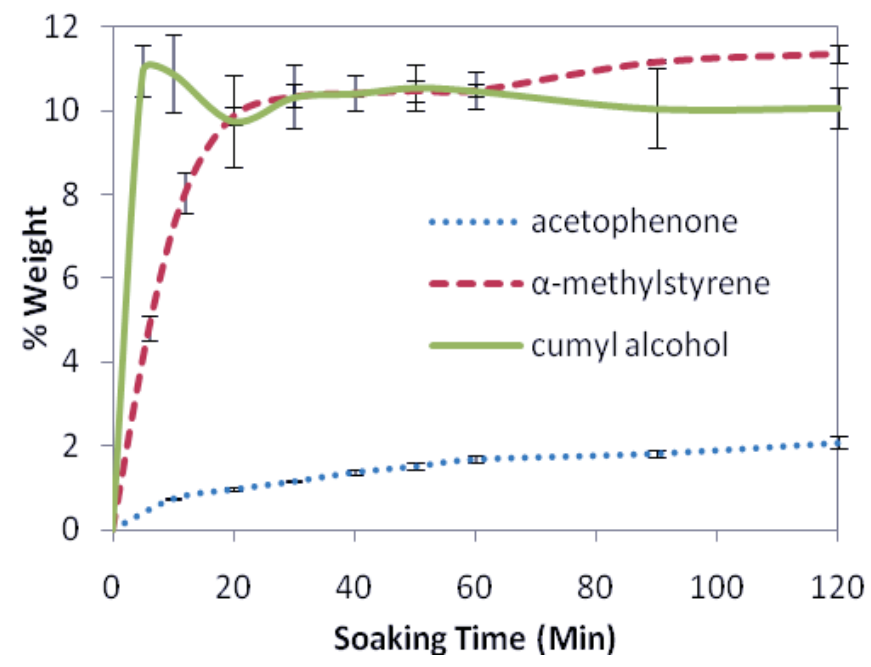

Figure 1. The Soaking rate of acetophenone, $\alpha$-methylstyrene and cumyl alcohol in LDPE.

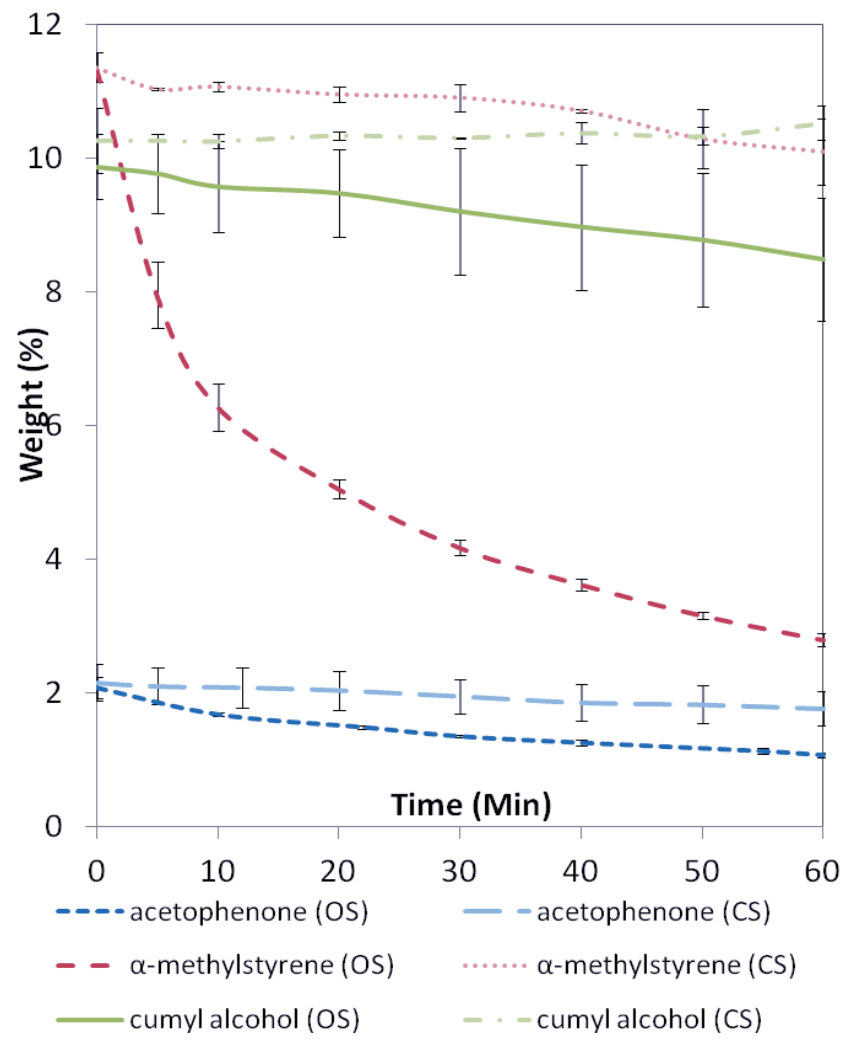

Figure 2. The decay of chemicals in soaked LDPE in open system (OS) and closed system (CS).

\subsection{SPACE CHARGE MEASUREMENT}

In space charge measurement, the PEA technique was employed. This technique is discussed in [10]. Semicon (a polymer consisting of polyethylene loaded with carbon black) and aluminium were used as the anode and cathode respectively. To measure space charge, a pulse voltage of 600 $\mathrm{V}$ with duration of $5 \mathrm{~ns}$ was applied to the sample to generate an acoustic signal wave. For calibration purposes, each sample 


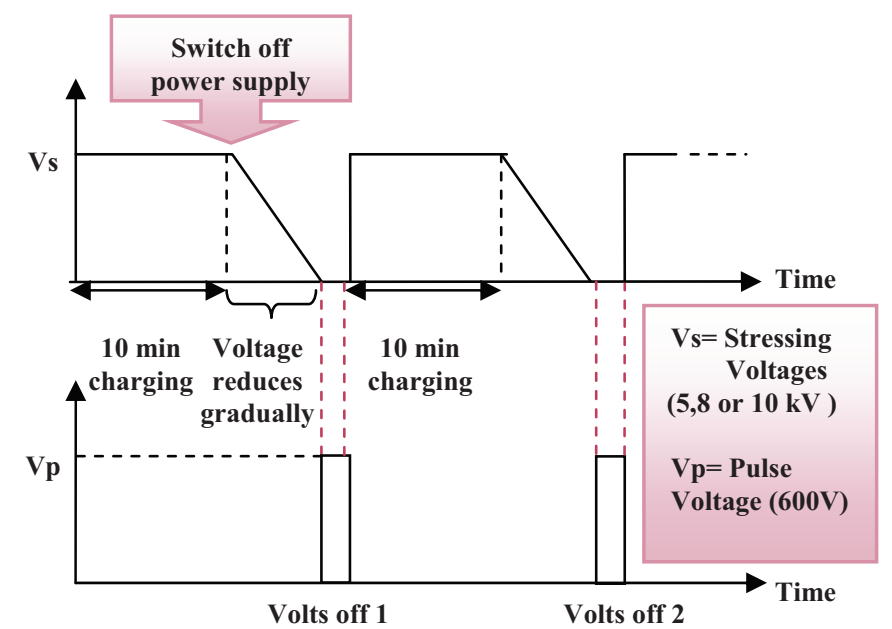

Figure 3. Voltage profile during Volts off measurement.

was stressed at $2 \mathrm{kV}$ dc voltage as discussed in [11] before applying three different positive dc voltages, 5, 8 and $10 \mathrm{kV}$ subsequently after the soaking process. The charge density pattern at $2 \mathrm{kV}$ is used as the reference signal when processing the PEA data in Lab View TM environment.

Space charge measurements were obtained during the charging and decay process. During the charging process, Volt off measurements were obtained every 10 minutes. The power supply was turned off and readings were taken 10 seconds after the dc voltage was removed. The sample was recharged immediately after readings were taken until the next reading time, this was carried out for a $1 \mathrm{~h}$ of charging period. Subsequently, the power supply was permanently removed, and the decay of the accumulated charge in specimen was measured for another hour. The schematic diagram of voltage profile during Volts off measurement is shown in Figure 3. To display charge profile more clearly, only Volts off and decay measurements are presented in this paper.

The Volts off results are presented in Figures 4 to 7 . Arrows in the figures show the changes in the charge density during the one hour measurement.

\section{EXPERIMENT RESULTS}

\subsection{VOLTS OFF MEASUREMENT RESULTS}

Figure 4 shows the charge density of untreated LDPE and is used as a reference to when comparing data from the treated samples. These studies are important to ensure that space charge data accumulated as a result of the byproducts will not be misinterpreted.

\subsection{CLEAN UNTREATED LDPE}

The data from untreated LDPE show that, for the sample stressed at $5 \mathrm{kV}$, the increasing stress time results in the charges of both polarities gradually increasing in the sample (Figure 4a). Negative charges are trapped in the region close to the cathode. It is also observed that the injected positive charges tend to move towards the cathode due to different

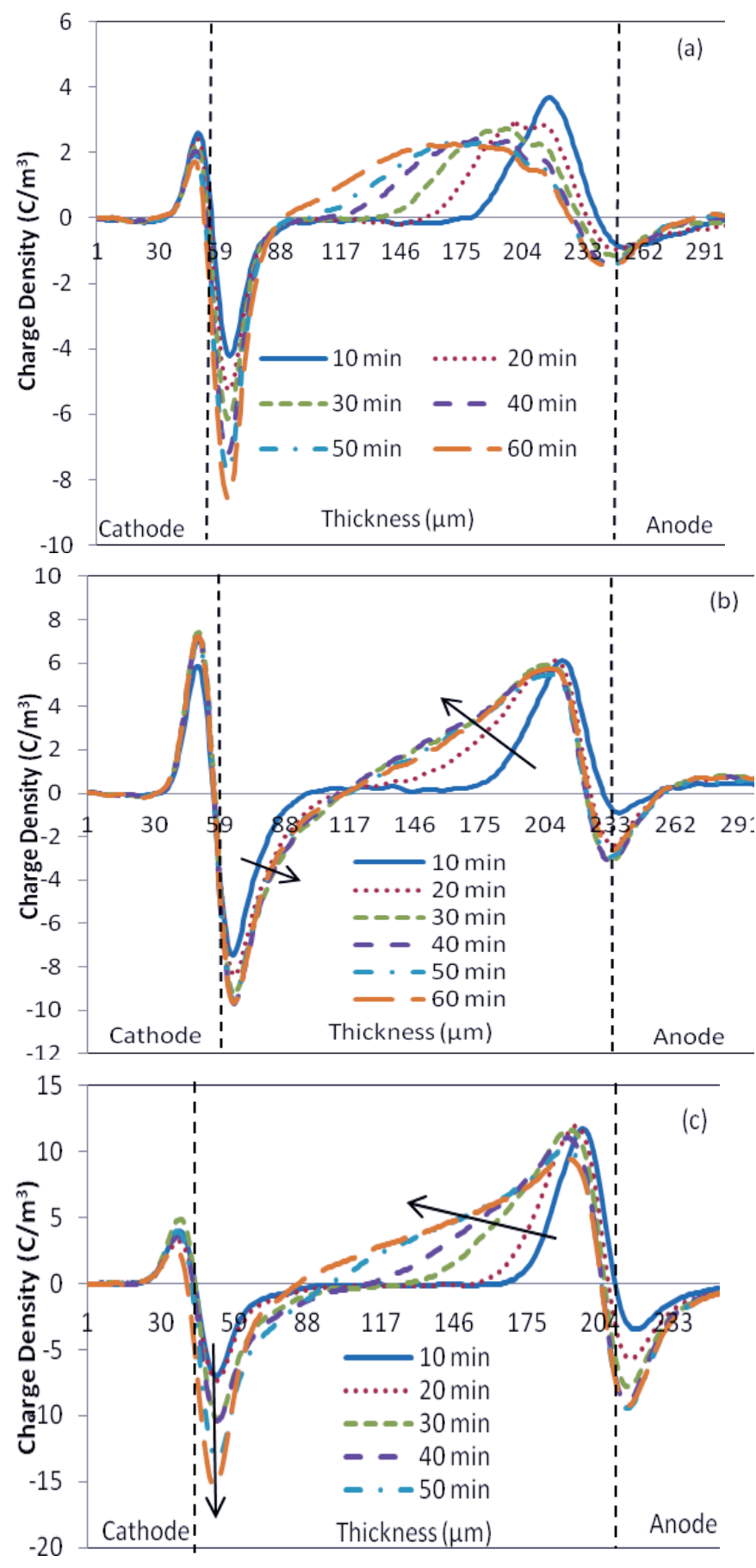

Figure 4. Charge density of $180 \mu \mathrm{m}$ clean LDPE; a) stressed at $5 \mathrm{kV}, \mathrm{b}$ ) stressed at $8 \mathrm{kV}, \mathrm{c}$ ) stressed at $10 \mathrm{kV}$, during Volts off condition.

polarity attraction. When the LDPE stressed at 8 and 10 $\mathrm{kV}$, a greater volume of negative charges are injected from the cathode and the charges drift slowly into the sample bulk. It is clear that the meeting point of positive and negative charges moves towards the middle of the sample with the increasing applied voltage.

\subsection{ACETOPHENONE}

Figure 5 represents space charge data for LDPE soaked in acetophenone, where negative charge domination is observed. 

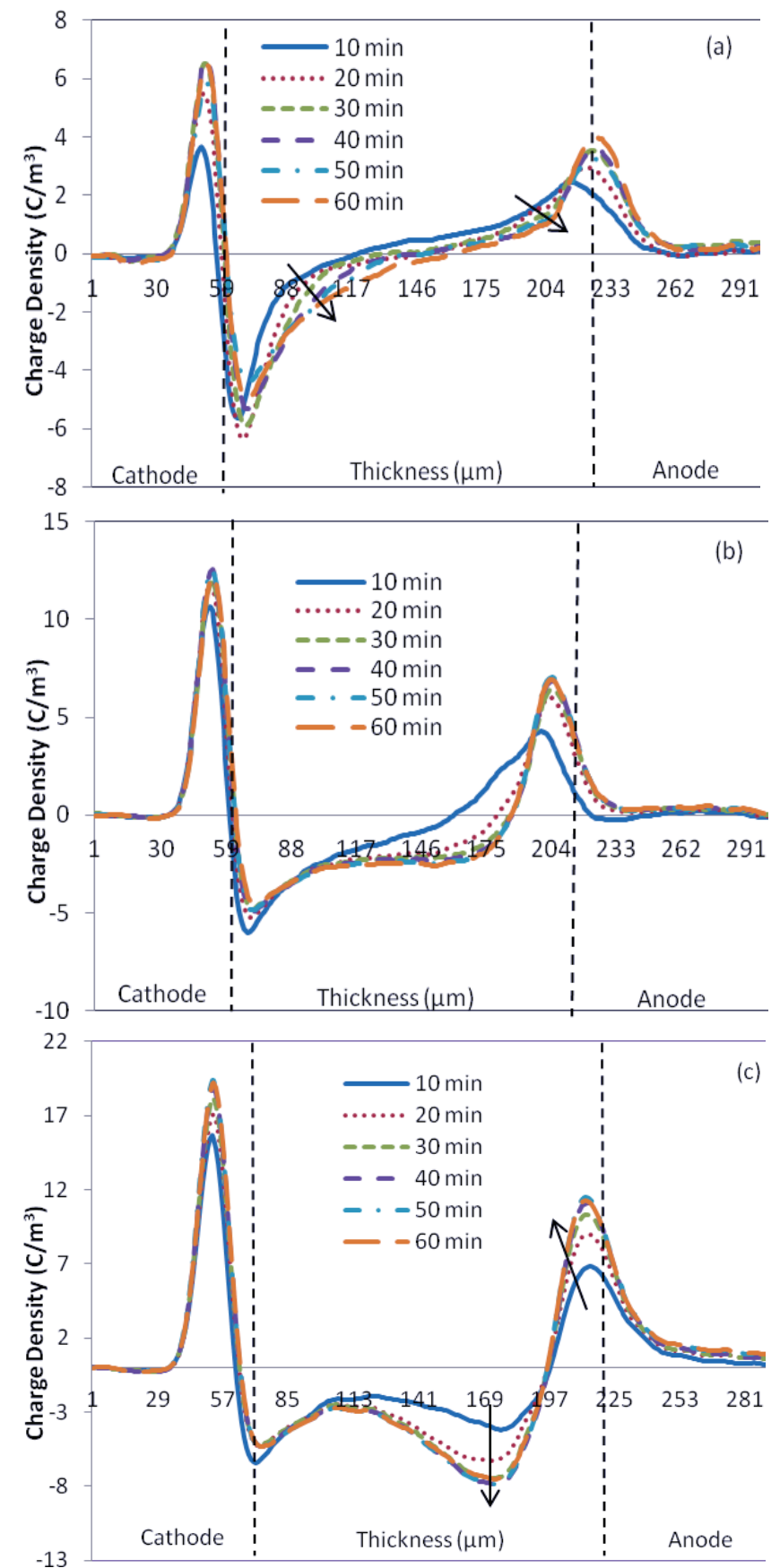

Figure 5. Charge density of $180 \mu \mathrm{m}$ acetophenone soaked LDPE; a) stressed at $5 \mathrm{kV}$, b) stressed at $8 \mathrm{kV}$, c) stressed at $10 \mathrm{kV}$, during Volts off condition.

In the vicinity of the anode, the amount of positive charges decrease over time, indicating that either the positive charges migrate towards the nearby electrode, or the amount of negative charges are greater in that specific area. It is observed that the amount of negative charges that move into the bulk of the sample, towards to anode, is proportional to the stressing time. This observation can be seen at all three charging voltages and is more noticeable at higher voltage. As the positive charges from the anode are suppressed, one observes distinguishable differences in the charge profile of
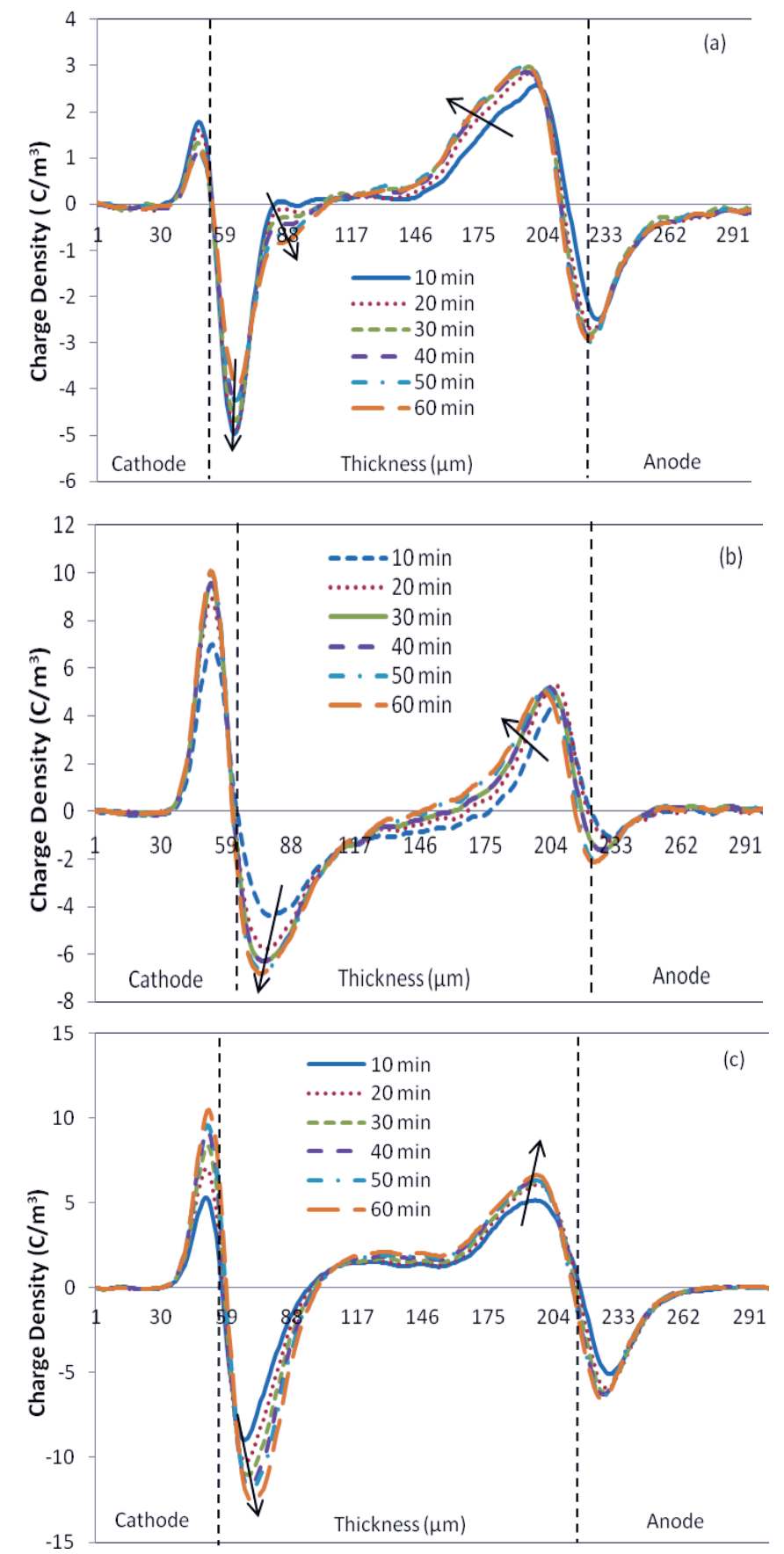

Figure 6. Charge density of $180 \mu \mathrm{m} \alpha$-methylstyrene soaked LDPE; a) stressed at $5 \mathrm{kV}$, b) stressed at $8 \mathrm{kV}$, c) stressed at $10 \mathrm{kV}$, during Volts off condition.

LDPE soaked in acetophenone compared to an untreated sample.

\section{4 $\alpha$-METHYLSTYRENE}

Charge density of the $\alpha$-methylstyrene soaked LDPE, shows a different characteristic as illustrated in Figure 6 . The charge profiles for these samples are similar to those seen for untreated LDPE, where the positive charges dominate the sample bulk whereas the negative charges are trapped near the 

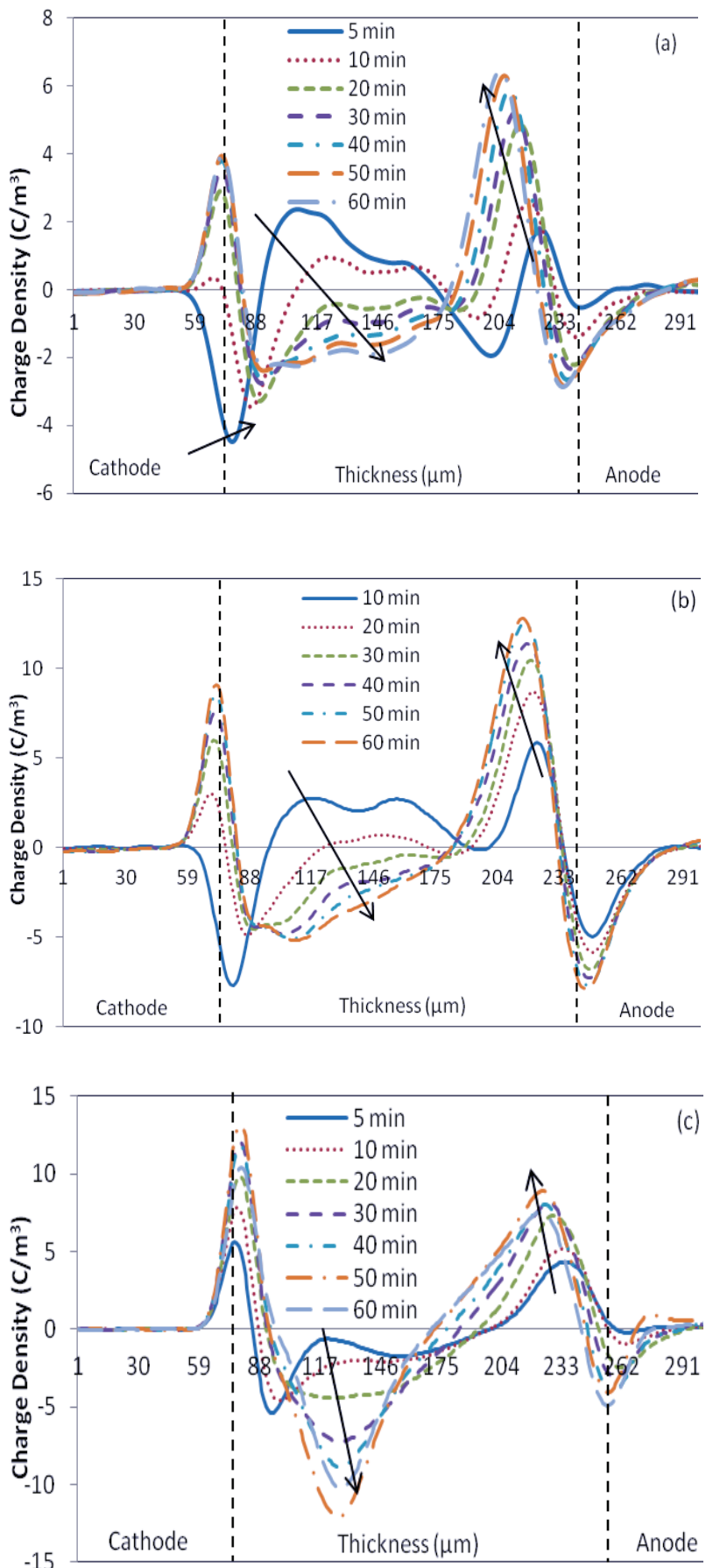

Figure 7. Charge density of $180 \mu \mathrm{m}$ cumyl alcohol soaked LDPE; a) stressed at $5 \mathrm{kV}, \mathrm{b}$ ) stressed at $8 \mathrm{kV}$, c) stressed at $10 \mathrm{kV}$, during Volts off condition.

cathode. Slower charge built up is observed in the $\alpha$ methylstyrene soaked sample stressed at $5 \mathrm{kV}$ and $8 \mathrm{kV}$. However, at $10 \mathrm{kV}$ (Figure 6c) positive charges already accumulate in the bulk of the sample within the first 10 minutes of stressing. Similarly to Figure 6, authors have reported [2] a rapid migration of positive charges in a $\alpha$ methylstyrene soaked sample, it is concluded that $\alpha$ methylstyrene has a greater effect on the positive charge migration than acetophenone as it can permeate faster into the polymer structure.

\subsection{CUMYL ALCOHOL}

The space charge characteristic of LDPE soaked in cumyl alcohol is different from the two former chemicals discussed. The charge density of the sample is shown in Figure 7. Cumyl alcohol causes charge accumulation of both charge polarities with heterocharges appeared when the sample is stressed at $5 \mathrm{kV}$ and $8 \mathrm{kV}$. Cumyl alcohol introduces a greater charge injection into the sample compared to the other byproducts, especially at $5 \mathrm{kV}$ and $8 \mathrm{kV}$. After 10 minutes of charging, the negative charges in samples stressed at $5 \mathrm{kV}$ and $8 \mathrm{kV}$, migrate into the bulk, reducing the height of the positive peak. After 20 minutes, the positive peak completely disappears and negative charges accumulate in the bulk of sample. Similar observations are seen for the negative peak near the anode. However, as the voltage is increased to 10 $\mathrm{kV}$, heterocharges can no longer be seen due to charge injection from the electrodes. These results have been previously reported in [12] but not discussed.

\section{SPACE CHARGE DECAY RESULTS}

By monitoring the charge decay after the applied voltage is removed, one can see the influence of the byproduct chemicals on the charge transportation of the insulator. By integrating the space charge density $\rho(x, t ; E)$ over the insulation thickness at time $t$, the amount of charge in the sample, $q(t ; E)$ is obtained;

$$
q(t ; E)=\int_{0}^{L}|\rho(x, t ; E)| \cdot S \cdot d x
$$

where 0 and $\mathrm{L}$ denote the position of the electrode excluding the charges at the electrodes, $\mathrm{E}$ is the electric field and $\mathrm{S}$ is the electrode area. The charge profile of the sample can be analysed as the total charge value during decay, plotted over time. The results of this calculation are presented in Figure 8.

The effect of the chemicals on the total charge is the greatest at the higher voltages, although no big differences are observed at a lower voltage. In samples charged at $5 \mathrm{kV}$ and $8 \mathrm{kV}$, cumyl alcohol introduces more charge accumulation compared to the charges in the clean untreated LDPE. Acetophenone and $\alpha$-methylstyrene reduce the amount of total charge accumulated in the LDPE. At $10 \mathrm{kV}$, acetophenone and cumyl alcohol contribute to more charge accumulation to the untreated LDPE.

Comparing all soaked samples and the clean untreated LDPE, $\alpha$-methylstyrene has the least effect on the charge accumulation in the insulator as it reduces the total charge accumulation compared to the all samples. This is clear in all three stressing voltages where $\alpha$-methylstyrene soaked LDPE has the least charges in the sample including the clean LDPE. Comparatively, cumyl alcohol shows a clear contribution to the charge built up within the insulator. Heterocharges appear near the electrodes to increase the stress at the electrode interface and therefore enhances the charge injection into the sample. 

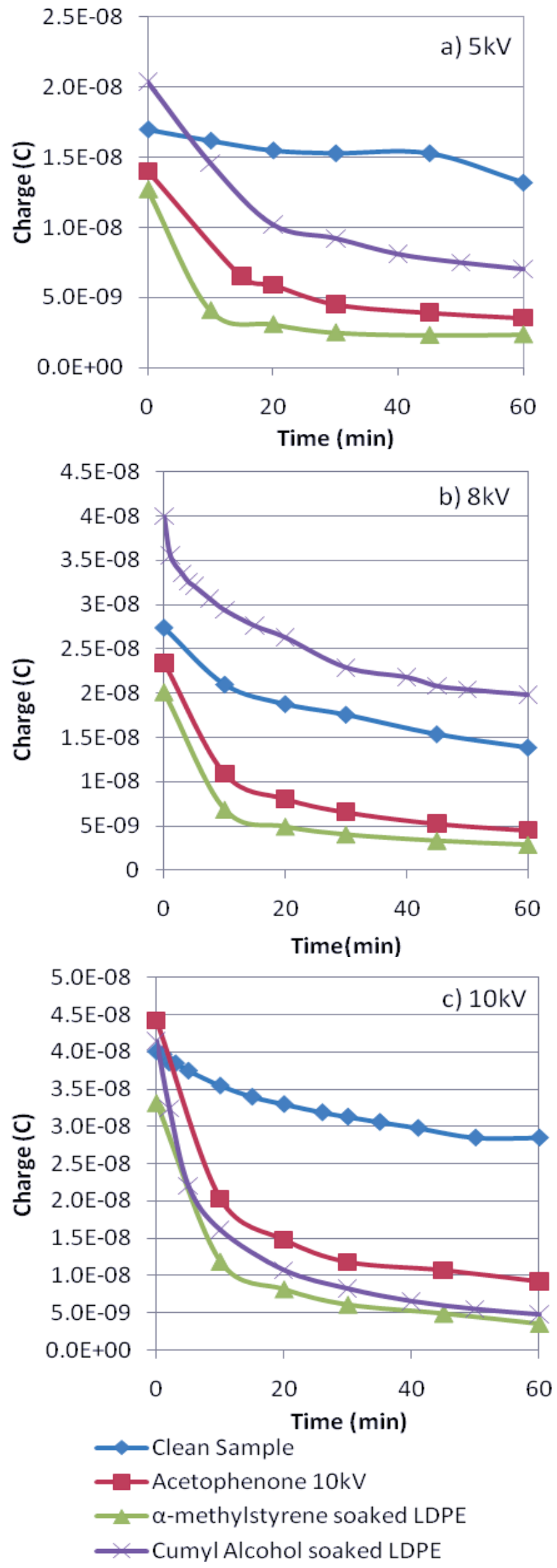

Figure 8. The total charge in the samples that stressed at $5 \mathrm{kV}, 8 \mathrm{kV}$ and $10 \mathrm{kV}$.
Despite the increase of charge injection and accumulation within the insulator, the chemicals speed up the decay process, particularly in the first 15 to 20 minutes. From this point, the charge decay is comparable to the untreated LDPE. From the charge decay results, LDPE soaked in $\alpha$ methylstyrene has the greatest rate of decay followed by acetophenone and cumyl alcohol. $\alpha$-methylstyrene results in $80 \%$ of the original charges within a sample to decay. As the rate of decay is commonly associated with shallow and deep traps, where rapid decay is observed in the former [13], one can conclude that the chemical byproducts reduce the number of charges trapped in the deep traps. This is demonstrated by a slower rate of decay in a smaller number of charges, as seen in the decay curves. Based on the results one assumes that the charges will initially fill the shallow traps prior to the deep traps, this hypothesis has been verified recently [14]. It is reasonable to suggest that the byproduct chemicals modify the trapping characteristics of LDPE in two possible ways,

1) by increasing the population of the shallow traps

2) by reducing the number of deep traps in the LDPE, replacing them with the shallow traps.

In untreated LDPE, deep electron traps are often found in regions of reduced density, such as sub-microvoids with surrounded polymer chains [15]. These voids and naturally occurring spaces between the crystalline structures will fill with chemicals in the soaking process and result in a change in the charge trapping and de-trapping characteristics associated with the region. This is dependent on the type of bonding the chemical byproducts induce within the system such as benzene ring, carbonyl group, double bond, and hydroxyl groups.

\section{TWO BYPRODUCTS IN SAMPLE}

Table 2. The Mixture of chemical byproducts.

\begin{tabular}{c|c}
\hline Sample & Chemicals \\
\hline a- $\alpha$ & LDPE in acetophenone plus \\
& $\alpha$-methylstyrene \\
a-c & LDPE in acetophenone plus \\
& cumyl alcohol \\
\hline $\boldsymbol{\alpha}$-c & LDPE in $\alpha$-methylstyrene plus \\
& cumyl alcohol \\
\hline
\end{tabular}

The analysis made above is based on the assumption that the chemical function of the byproducts act separately from each other. At this stage, it is difficult to achieve a similar mixture ratio to that in practice via soaking process. This is because of the difficulty to control the amount of byproducts in the soaked sample and at the same time have a uniform distribution across the film thickness. Our main concern here is 

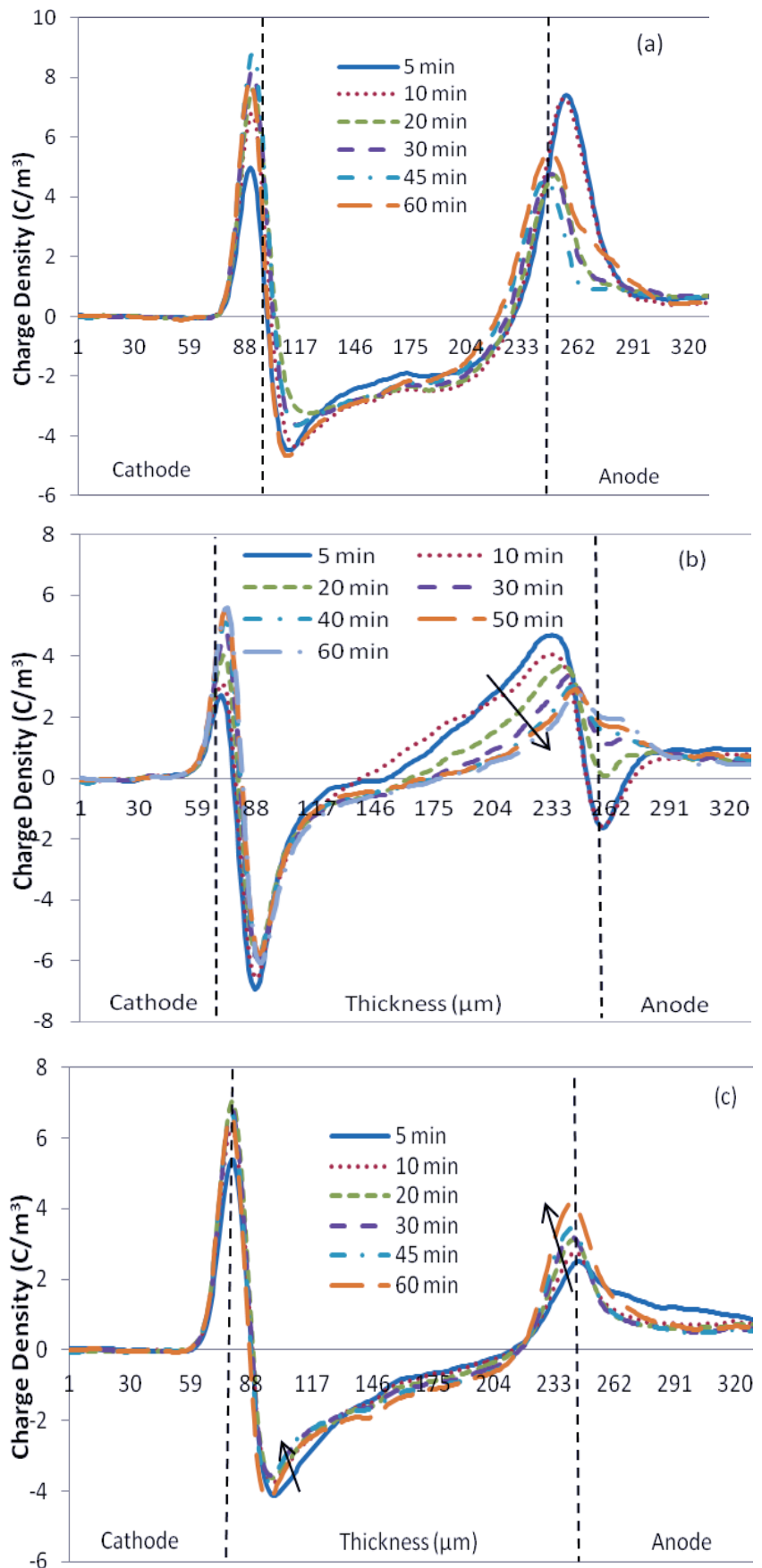

Figure 9. Charge density profile of (a) Sample a- $\alpha$ (b) Sample a-c and (c) Sample $\alpha$-c, during Volts off Condition. Arrow shows the charge movement during one hour charging.

to examine potential interactions amongst different byproducts. As it is difficult to see these effects with a mixture of three byproducts, only two byproducts are mixed at one time. The results are compared to those obtained in the previous section.

To do so, LDPE films were placed into a mixture of two chemicals at room temperature. The samples for space charge measurements are shown in Table 2. Similar space charge measurement procedures as explained above were applied to

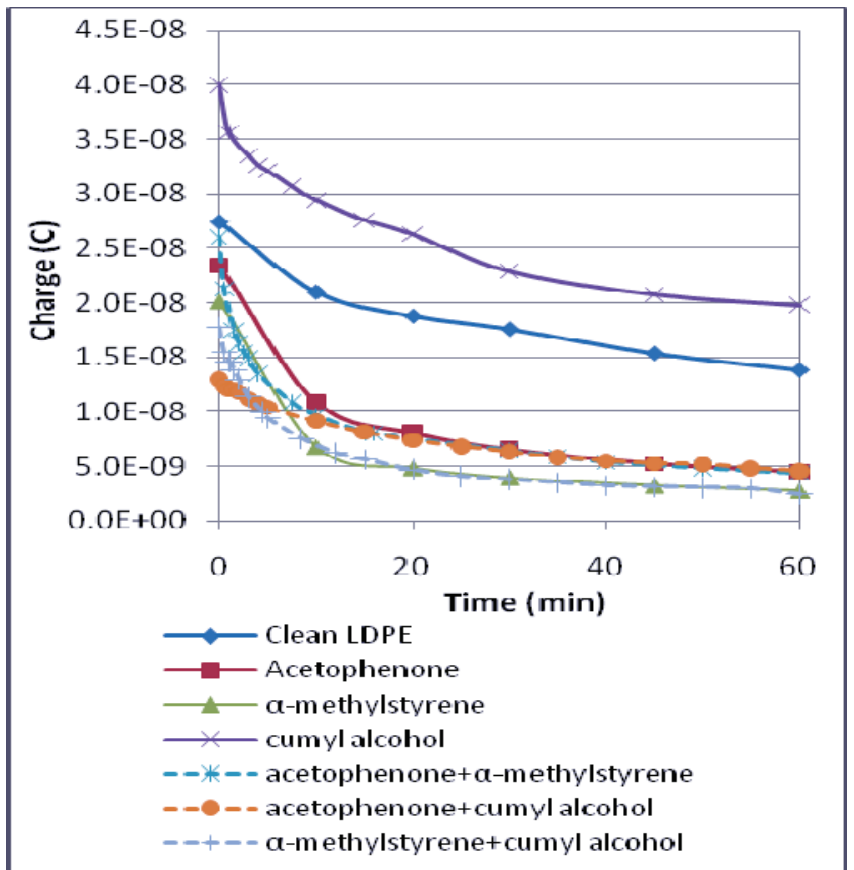

Figure 10. Total charge decay in samples that stressed at $8 \mathrm{kV}$.

the samples. Space charge formation was monitored at $8 \mathrm{kV}$ and the results are presented in Figure 9.

For Sample a- $\alpha$, the charge density profile illustrates how negative charges dominate the sample bulk. This profile is similar to data obtained from acetophenone soaked LDPE, which suggests that acetophenone has a greater influence than $\alpha$-methylstyrene in terms of controlling the charge build up. The former byproduct suppresses positive charge injection from the anode. Similar characteristics are observed in Figure $6 b$.

The influence of acetophenone over the other byproducts is also shown in Sample a-c. The amount of positive charge that decreases with charging time shows that the positive charges are suppressed. This observation is believed to be associated with the existence of acetophenone in the sample. No heterocharges appeared in Sample a-c and Sample $\alpha$-c, although cumyl alcohol was present in the sample.

In Sample $\alpha$-c, negative charges migrate from the cathode to the sample bulk. As a result, more negative charge is seen in the sample. It is believed that some positive charges are trapped in the vicinity of the anode, this is consistent with the space charge profile in $\alpha$ methylstyrene and cumyl alcohol soaked LDPE. However, due to low resolution, these charges appear in only one positive peak. As the charge dynamics do not show any distinctive pattern associated with any of the individual byproducts, a conclusion cannot be drawn as to which byproduct is the most dominant.

The total charge accumulation in the samples calculated using equation (1) are presented in Figure 10. The total charge from samples soaked in single byproduct is also included in the figure for comparison. After being stressed for an hour, the total charge accumulated in Sample a- $\alpha$ is 
the highest followed by Sample $\alpha-c$ and Sample a-c. Despite having the least total charge, the rate of charge decay in Sample a-c is low relative to the other two samples. It is believed that the presence of $\alpha$-methylstyrene in samples $a-\alpha$ and $\alpha$-c cause a faster rate of decay. The result indicates that in terms of charge accumulation, it is rather difficult to see which byproduct causes the most charge injection into the insulator. However, $\alpha$ methylstyrene maintains its characteristic as the charge decay accelerator while in the existence of other byproducts in the insulator.

\section{CONCLUSION}

The effects of acetophenone, $\alpha$-methylstyrene and cumyl alcohol on space charge formation have been evaluated. Where single byproducts exist in the sample, cumyl alcohol introduces homocharges and heterocharges which cause a greater amount of space charges to form in LDPE. Heterocharges increase the stress at the electrodes and hence

intensifies the charge injection. As a result, heterocharges gradually disappear as the charging process is continued. Acetophenone assists the movement of negative charge in the sample bulk and the byproduct introduces more charge at higher voltages. $\alpha$-methylstyrene however, reduces the amount of total charge introduced into the insulator as the charges are suppressed near the electrodes.

In terms of charge decay, the byproducts induce the decay process. $\alpha$-methylstyrene causes the fastest charge decay followed by acetophenone and then cumyl alcohol. With more than two byproducts in a sample, $\alpha$ methylstyrene retains its characteristic as the 'catalyst' of the charge decay process. Acetophenone retains its charge profile during charging process, with more negative charges drifting into the bulk towards the anode.

\section{REFERENCES}

[1] T. Andrews, R. N. Hampton, A. Smedberg, D. Waldm, V. Waschk and W. Weissenberg, "The Role of Degassing in XLPE Power Cable Manufacture" IEEE Electr. Insul. Mag., Vol. 22, No.6, pp. 5-16, 2006.

[2] Y. Ohki, N. Hirai, K. Kobayashi, R. Minami, M. Okashita and T. Maeno, "Effects of Byproducts of Crosslinking Agent on Space Charge Formation in Polyethylene-Comparison Between Acetophenone and $\alpha$-methylstyrene", IEEE Conf. Electr. Insul. Dielectr. Phenomena (CEIDP), Victoria, BC, Canada, pp. 535-538, 2000.

[3] G.C. Montanari, "Electrical Degradation Threshold of Polyethylene Investigated by Space Charge and Conduction Current Measurements", IEEE Trans. Dielectr. Electr. Insul., Vol. 7, pp. 309$315,2000$.

[4] Y. Sekii, T. Ohbayashi, T. Uchimura, K. Mochizuki and T. Maeno, "The effects of material properties and inclusions on the space charge profiles of LDPE and XLPE", IEEE Conf. Electr. Insul. Dielectr. Phenomena (CEIDP, Cancun, Mexico, pp. 635-639, 2002.
[5] Y. Sekii, T. Ohbayashi, T. Uchimura, T. Hukuyama and T. Maeno, "A Study On the Space Charge Formation in XLPE", IEEE Conf. Electr. Insul. Dielectr. Phenomena (CEIDP), Kitchener, Ontario , Canada, pp. 469 - 472, 2001.

[6] N. Hirai , Y. Maeno , T. Tanaka, Y. Ohki, M. Okashita and T. Maeno, "Effect of Crosslinking on Space Charge Formation in Crosslinked Polyethylene", IEEE Conf. Properties Applications Dielectr. Materials, Nagoya, Japan, pp. 917-920, 2003.

[7] G.C. Montanari, C. Laurent, G. Teyssedre, A. Campus and U.H. Nilsson, "From LDPE to XLPE: Investigating the change of electrical properties. Part I: Space charge, Conduction and lifetime", IEEE Trans. Dielectr. Electr. Insul., Vol. 12, pp.438-446, 2005.

[8] N. Hirai, Y. Maeno, T. Tanaka, Y. Ohki, M. Okashita and T. Maeno, "Roles of cumyl alcohol and crosslinked structure in homo-charge trapping in crosslinked polyethylene, IEEE Conf. Electr. Insul. Dielectr. Phenomena (CEIDP), Albuquerque, NM, USA, pp. 213216, 2003.

[9] N. Hirai, R. Minami, T. Tanaka, Y. Ohki, M. Okashita and T. Maeno, "Chemical Group in Crosslinking Byproducts Responsible for Charge Trapping in Polyethylene", IEEE Trans. Dielectr. Electr. Insul., Vol. 10, pp. 320-330, 2003.

[10] Y. Zhu, D. Tu and T. Takada, "Mathematical analysis and interpretation of pulsed electro-acoustic system", IEEE Int'l. Conf. Properties Applications Dielectr. Materials (ICPADM), Xi'an, China, pp. 63-66, 2000.

[11] G. Chen, Y.L. Chong and M. Fu, "Calibration of the Pulsed Electroacoustic Technique in the Presence of Trapped Charge", Measurement Science and Technology, Vol. 17, pp.1974-1980, 2006.

[12] N. Hirai, R. Minami, Y. Ohki, M. Okashita and T. Maeno, "Effects of byproducts of dicumyl peroxide on space charge formation in polyethylene", IEEE Int'l. Conf. Conduction and Breakdown in Solid Dielectr. (ICSD), Eindhoven, Netherlands, pp. 450-455, 2001.

[13] T. Mizutani, C. Zhang and M. Ishioka, "Space Charge Behavior in LDPE and Its Blend Polymers", 11th Int'l. Sympos. Electrets, Melbourne, Australia, pp. 147-150, 2002.

[14] G. Chen and Z. Xu, "Charge Trapping and Detrapping in Polymeric Materials", J. Appl. Phys., Vol. 106, pp.123707 - 123707-5, 2009.

[15] J. P. Jones, J. P. Llewellyn and T.J. Lewis, "The Contribution of Field-Induced Morphological Change to the Electrical Aging and Breakdown of Polyethylene", IEEE Trans. Dielectr. Electr. Insul., Vol. 12, pp. 951-966, 2005.

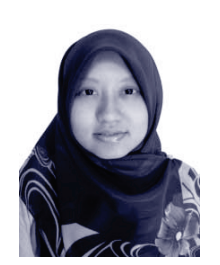

Nuriziani Hussin was born in Pahang, Malaysia in 1984. She received the Bachelors degree in electrical engineering from the School of Electronics and Computer Science at the University of Southampton in 2007. She is currently pursuing the Ph.D. degree at the Tony Davies High Voltage Laboratory at the University of Southampton.

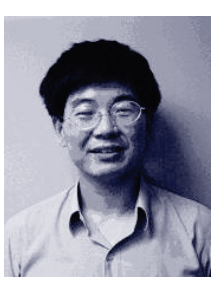

George Chen was born in China in 1961. He received the B.Eng. and M.Sc. in 1983 and 1986, respectively in electrical engineering from Xian Jiaotong University,China. After he obtained the $\mathrm{Ph} . \mathrm{D}$. degree in 1990 in electrical engineering from The University of Strathclyde, UK, he joined the University of Southampton as a postdoctoral research fellow and became a senior research fellow subsequently. In 1997 he was appointed as a research Lecturer and was promoted to a Reader in 2002. Over the years, he has developed a wide range of interests in high voltage engineering and electrical properties of materials and published over 150 papers. 